\title{
Multigeneration Inheritance through Fertile XX Carriers of an NROB1 (DAX1) Locus Duplication in a Kindred of Females with Isolated XY Gonadal Dysgenesis
}

\author{
Michela Barbaro, ${ }^{1}$ Jackie Cook, ${ }^{2}$ Kristina Lagerstedt-Robinson, ${ }^{1}$ and Anna Wedell ${ }^{1}$ \\ ${ }^{1}$ Department of Molecular Medicine and Surgery, Karolinska Institut, Karolinska University Hospital, CMM L8:02, \\ 17176 Stockholm, Sweden \\ ${ }^{2}$ Department of Clinical Genetics, Sheffield Children's Hospital, Sheffield S 102 TH, UK
}

Correspondence should be addressed to Michela Barbaro, michela.barbaro@ki.se

Received 31 August 2011; Revised 21 November 2011; Accepted 21 November 2011

Academic Editor: Gil Guerra-Junior

Copyright ( $) 2012$ Michela Barbaro et al. This is an open access article distributed under the Creative Commons Attribution License, which permits unrestricted use, distribution, and reproduction in any medium, provided the original work is properly cited.

\begin{abstract}
A $160 \mathrm{~kb}$ minimal common region in Xp21 has been determined as the cause of XY gonadal dysgenesis, if duplicated. The region contains the MAGEB genes and the NROB1 gene; this is the candidate for gonadal dysgenesis if overexpressed. Most patients present gonadal dysgenesis within a more complex phenotype. However, few independent cases have recently been described presenting with isolated XY gonadal dysgenesis caused by relatively small NROB1 locus duplications. We have identified another NROB1 duplication in two sisters with isolated XY gonadal dysgenesis with an X-linked inheritance pattern. We performed Xinactivation studies in three fertile female carriers of three different small NROB1 locus duplications identified by our group. The carrier mothers did not show obvious skewing of X-chromosome inactivation, suggesting that NROB1 overexpression does not impair ovarian function. We furthermore emphasize the importance to investigate the NROB1 locus also in patients with isolated $\mathrm{XY}$ gonadal dysgenesis.
\end{abstract}

\section{Introduction}

Xp21 duplications containing the NROB1 (DAX1) locus have long been known to be associated with XY gonadal dysgenesis (GD). A 160-kb minimal common region that, if duplicated, causes XY GD has also been determined [1] by comparing several patients with Xp rearrangements. This minimal region contains the MAGEB genes and the NROB1 (DAX1) gene, with NROB1 as the strongest candidate to cause gonadal dysgenesis if overexpressed $[1,2]$. In fact NROB1 has an embryonic expression compatible with a role in sex determination and in adrenal and hypothalamic function in mice [3], and several functional roles in the hypothalamic-pituitary-adrenal-gonadal axis have been reported [4]. However, XY mice transgenic for Dax1 show delayed testis development and sex reversal only if the transgene is tested against a weak Sry allele [5]. In humans, the effect of NROB1 overexpression is also shown by XY patients with $1 \mathrm{p}$ duplications including the WNT4 gene;
WNT4 is a signalling molecule that has been shown to upregulate NROB1 and XY patients with WNT4 duplications present with abnormal gonadal development [6]. Another indirect proof in human patients is provided by patients with XY GD caused by NR5A1 (SF1) haploinsufficiency. NR0B1 has been reported to inhibit NR5A1, with consequent reduction of steroidogenesis and AMH production, thus it can be hypothesized that overexpression of NROB1 leads to gonadal dysgenesis via inhibition of NR5A1.

Although the aforementioned data support NROB1 as the gene responsible for GD, a direct proof in a patient is still missing as a duplication containing only the NROB1 gene has not been identified yet in XY patients with GD. All duplications reported so far also contain at least some of the MAGEB genes that have specific testis expression but yet unknown function; thus, they cannot be ignored.

Most patients reported before the development of arrayCGH had XY GD as part of a more complex phenotype 
which also included dysmorphic features and/or mental retardation (for review $[7,8]$ ). This is explained by the fact that most patients have been identified by conventional karyotyping; thus, they carry large genomic rearrangements involving several genes.

We have previously described two NROB1 locus duplications in three patients with isolated XY GD; two sisters with complete XY GD [9] and a boy with partial XY GD [10]. Both duplications were of a relatively small size $(\leq 800 \mathrm{~kb})$. In fact they were not identified by conventional karyotyping but by array-CGH and MLPA, respectively. This indicates that NROB1 locus duplications should be investigated also in cases with isolated XY GD and not only when GD, in partial or complete form, is part of a more complex phenotype. In fact two other groups have applied array-CGH to patients with 46,XY GD and have identified additional NROB1 locus duplications $[11,12]$.

We developed a DSD probe set for MLPA analysis to screen for dosage imbalances of several genes involved in DSD, with particular attention to genes involved in GD [10]. This probe set includes probes for NROB1 and also the $M A G E B 1$ gene, thus enabling us to detect small NROB1 locus duplications. Here, we present a NROB1 locus duplication responsible for isolated XY GD identified in a large English family. We also analysed the X-inactivation patterns in fertile female carriers of each of the three small NROB1 locus duplications identified by our group. Female carriers of macroscopic Xp21 duplications are thought to be healthy and fertile due to skewed $\mathrm{X}$-inactivation, preferentially inactivating the duplicated chromosome and thereby protecting the individual from increased gene expression. Similarly, a skewed inactivation in carriers of the small duplications would indicate a deleterious effect on increased NROB1 (DAX1) gene expression on ovarian function.

\section{Materials and Methods}

2.1. Patients. We studied an English family (Figure 1) with two sisters with isolated 46,XY GD. An X-linked inheritance of the defect was suspected on the basis that, through the maternal line, there is a relative who is an XY female. Informed consent and ethical approval were obtained.

Patient VI.1 (proband) presented with primary amenorrhea at 16 years of age. She had female external genitalia. The endocrine profile showed markedly elevated gonadotropins and low oestradiol. The testosterone level was $1 \mathrm{nmol} / \mathrm{L}$ and androstenedione was $2.4 \mathrm{nmol} / \mathrm{L}$. Chromosomal examination and revealed a 46,XY karyotype. At ultrasound examination and the vagina was normal with a small prepubertal uterus of $1.8 \mathrm{~mL}$ of volume. A small amount of tissue of $0.5 \mathrm{~mL}$ volume was visible in the region of the right gonad, no follicles were identified within it. No ovarian tissue was identified on the leftside; however, this may be due to technical problem rather than the gonad being absent. At 17 years and 5 months of age, she underwent gonadectomy. Histological examination revealed fallopian tubes, and streak gonads. Ovarian-type stroma could be detected, and in one area some follicle cells could be demonstrated.

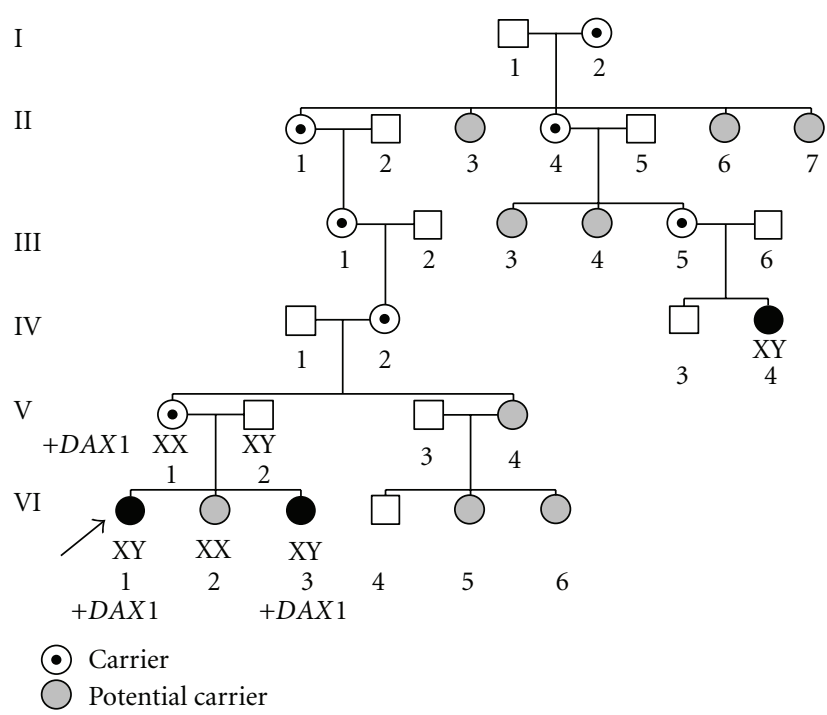

FIgURE 1: Family pedigree. Pedigree of a family with two sisters with 46,XY gonadal dysgenesis. +DAX1 indicates the subjects that carry the X chromosome containing the NROB1 locus duplication. $\mathrm{XX}$ and $\mathrm{XY}$ have been added underneath some subjects indicating a 46 , XX or 46,XY karyotype, respectively. Mandatory female carriers and potential carriers are marked.

Patient VI.3 is the younger sister of patient I1. She also had a 46,XY karyotype. Ultrasound examination, at 12 years and 4 months of age, revealed a prepubertal uterus, the right gonad had a $0.2 \mathrm{~mL}$ volume, while no left gonad was seen. Histological examination after gonadectomy at 12 years and 11 months of age showed the presence of unremarkable fallopian tubes, ovarian stroma cells, and gonadoblastoma, bilaterally.

Subject VI.2 has a 46,XX karyotype, she is an adult, and at the moment she does not wish to know if she is a carrier or not. After genetic counselling, no genetic investigation has been performed for this subject.

Patient VI.4 is a female with a 46,XY karyotype; however, no more information is available. No genetic investigation was performed as DNA was not available. It is very likely that she carries the same genetic defect as patient I1 and I3.

2.2. DNA. DNA was extracted from blood and/or EpsteinBarr virus-immortalized cell lines by phenol/chloroform extraction.

2.3. MLPA Analysis. For the initial MLPA analysis, the inhouse designed synthetic probe set DSD together with the EK1 reagent kit from MRC Holland (Amsterdam, The Nederland) was used as previously described [10]. Several probe mixes (Table 1) with different combinations of probes targeting sequences within the $\mathrm{Xp} 21$ region were used to further narrow down the breakpoint regions.

2.4. Fluorescence In Situ Hybridization. Fluorescence in situ hybridization (FISH) analysis on metaphase nuclei prepared from EBV-immortalized lymphocytes was performed as previously described [9], using the BAC clone RP11-662D2 


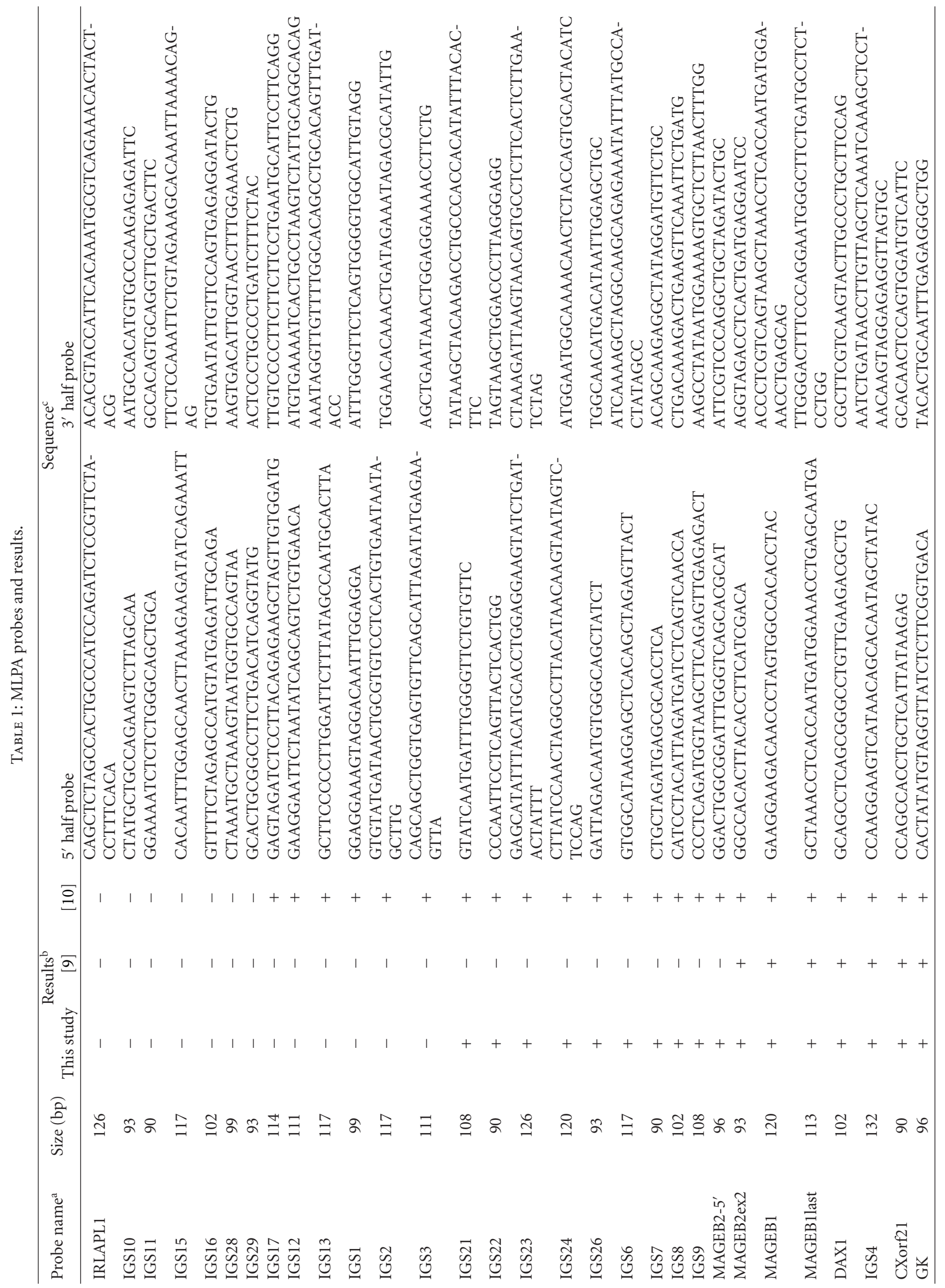




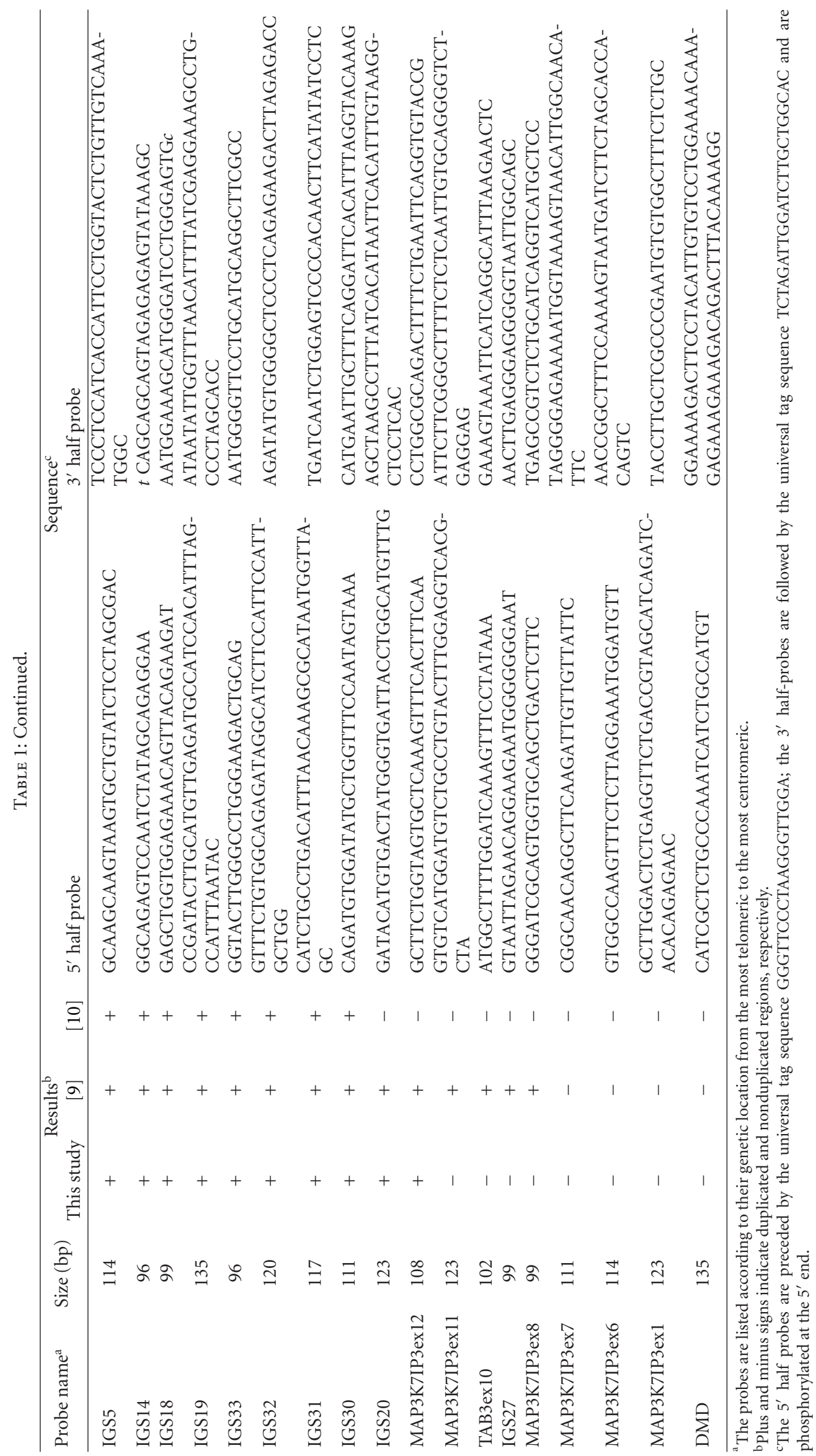


(CHORI BACPAC Resource Center, Oakland, CA, USA) which contains the NROB1 gene.

2.5. X-Inactivation Experiments. The $\mathrm{X}$-inactivation pattern was examined by the methylation analysis of the polymorphic CAG repeat within the androgen receptor gene [13]. Briefly, $250 \mathrm{ng}$ of DNA were digested using the methylation sensitive enzyme HpaI; digested and undigested DNA samples were amplified by PCR using a primer pair flanking the CAG repeat region as well the cleavage site, with the forward primer FAM labelled, Taq Gold (Applied Biosystems), 1X buffer II (Applied Biosystems), $200 \mu \mathrm{M}$ of each dNTPs, and $1.5 \mathrm{mM} \mathrm{MgCl}$. PCR products, together with the ROX HD400 size marker (Applied Biosystems), were size separated by capillary electrophoresis using a ABI3100 genetic analyser (Applied Biosystems, Warrington,UK). Trace data were analysed using the GeneMapper software (Applied Biosystems). Peak heights for the two digested alleles were corrected by the peak heights of the corresponding undigested alleles. The ratios of the skewed X-inactivation in digested samples were calculated by normalizing the sum of the two corrected alleles to $100 \%$. DNA was obtained from EBV-immortalized cell line and from blood. In addition, DNA from a male sample was included as control for complete digestion. Data are presented as the average of three independent experiments.

\section{Results}

3.1. MLPA Detection and Fine Mapping of the Duplication. The MLPA analysis with the DSD probe set detected a duplication of the DAX1 probe as well of the MAGEB1last probe, targeting the last exon of the MAGEB1 gene, in both affected sisters. MLPA was also used to further characterize the breakpoint region, using several probe mixes with different combination of probes targeting the Xp21 locus. We determined that the telomeric breakpoint region $(5.6 \mathrm{~kb})$ is located approximately $63 \mathrm{~kb}$ upstream of the $M A G E B$ genes, while the centromeric breakpoint region $(2.6 \mathrm{~kb})$ lies within intron 11 of the MAP3K7IP3 gene. Thus, the duplication has a minimal and maximal size of $679 \mathrm{~kb}$ and $687 \mathrm{~kb}$, respectively, and in addition to NROB1 it contains the MAGEB genes, CXorf21, GK and part of the $3^{\prime}$ region of the MAP3K7IP3 gene (Figure 2).

Parental DNA analysis revealed that the mother is a healthy carrier of the duplication. Table 1 summarizes all the probe pairs used and the results obtained. Together with these English patients, we present, for comparison, the results obtained for two Iranian sisters [9] and for an Italian patient, in which we previously narrowed down the breakpoint region [10].

3.2. Analysis of the Duplication Using FISH. Metaphase FISH analysis was performed to establish the location of the extra copy. On metaphases from the patient, only one signal for the clone RP11-662D2 containing the NROB1 gene was detected; on metaphases from the mother only one signal per $\mathrm{X}$ chromosome was detected, thus indicating an interstitial duplication and excluding translocation of X chromosome material onto another chromosome (data not shown).

3.3. X-Inactivation Studies. We analysed the $\mathrm{X}$-inactivation pattern in subject $\mathrm{V}-1$, and the methylation ratio between the $\mathrm{X}$-chromosome carrying the duplication and the normal chromosome, in EBV-immortalized lymphocytes, was $65 \%: 35 \%$. We performed X-inactivation studies also on two other mothers carrying different NROB1 locus duplication that have been previously described by our group $[9,10]$. Ratios between the $\mathrm{X}$-chromosome carrying the duplication and the normal chromosome were 58\%:42\% and $33 \%: 67 \%$, respectively.

These results indicate that in lymphocytes there is not a strong preferential methylation for the X-chromosome carrying the duplication.

\section{Discussion}

We present here a family where a relatively small NROB1 locus duplication is the genetic cause of isolated complete 46,XY GD. The duplication extends from the MAGEB gene to part of the MAP3K7IP3 gene, including NROB1, CXorf21, and $G K$ genes.

By bioinformatics evaluation of the breakpoint regions, we noted that within the telomeric breakpoint region there is a AluSc repeat of approximately $300 \mathrm{bp}$ that shares $85 \%$ and 84\% identity (BLASTN2.2.21 [14]) with two AluY repeats within intron 11 of the MAP3K7IP3 gene. These evolutionary young $A l u$ repeats may be involved in the duplication mechanism as they are found to be enriched near or within duplication junction [15]. We unfortunately have not been able to amplify and sequence the duplication junction so we could not determine the rearrangement mechanism and differentiate between a nonallelic homologous recombination (NAHR) or a nonhomologous end joining (NHEJ) mechanism. The latter was the mechanism of the duplication in a previously described family [9]. Actually, the failure, after several attempts, to amplify the duplication junction in two of the three duplications we have identified, makes us suspect that the duplications could be more complex and be generated by a FoSTes (Fork Stalling and Template Switching).

Xp21 duplications, as well deletions [16], including the NROB1 gene, are all different, thus they are caused by nonrecurrent rearrangements. This indicates that in this region there are several genomic elements that can lead to genomic rearrangements. These rearrangements will be different regarding size and genes involved. This is important to consider when a genetic test is chosen or developed to screen for these genomic disorders.

Two other groups have applied array-CGH to analyse patients with 46,XY gonadal dysgenesis and found additional Xp21 duplications $[11,12]$. Patients with large duplications presented XY gonadal dysgenesis associated to syndromic feature, while two patients with relatively smaller duplications $(<1 \mathrm{Mb})$ including NROB1 presented isolated $46, \mathrm{XY}$ gonadal dysgenesis (Figure 2). Thus, confirming our findings 


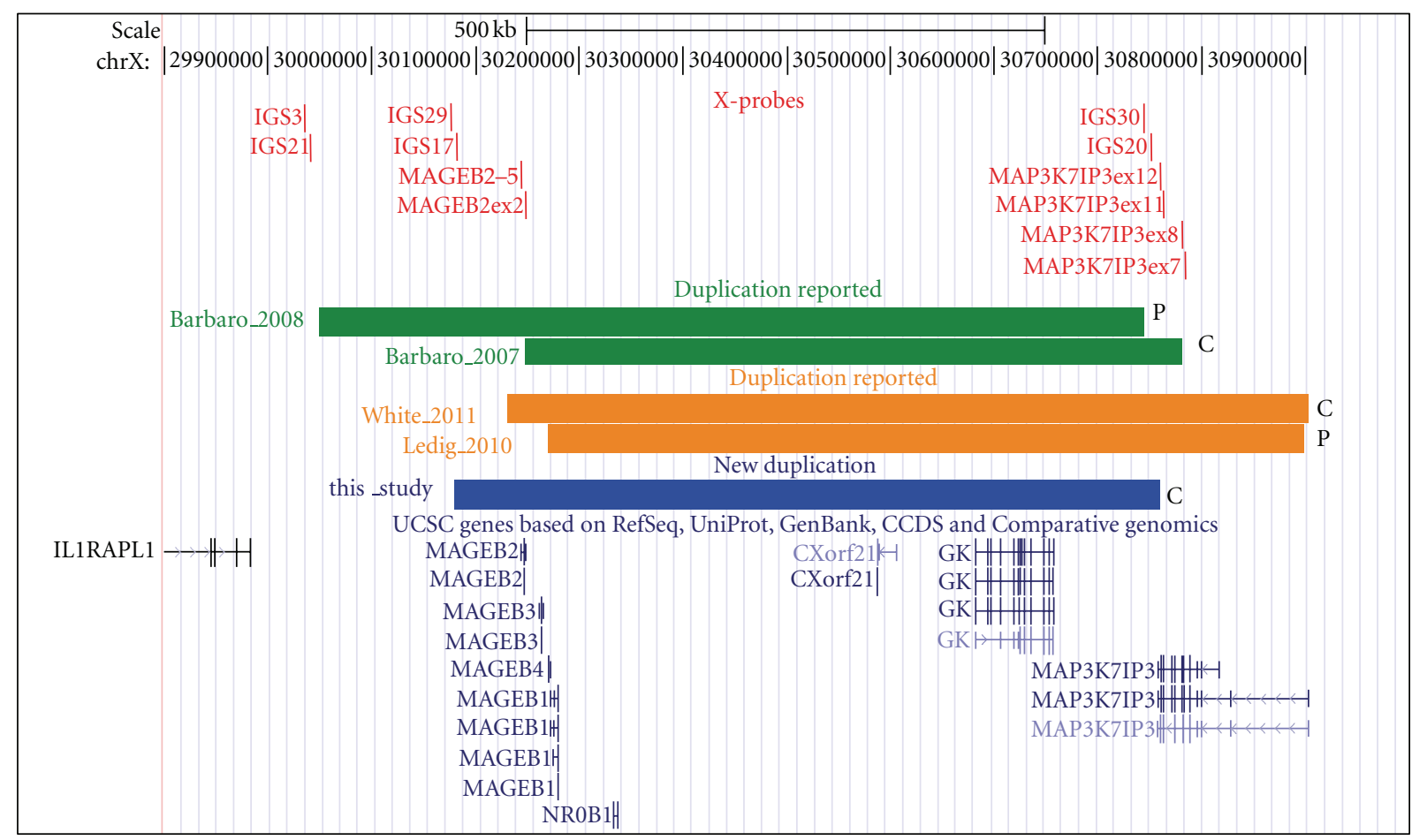

FIGURE 2: Comparison of NROB1 locus duplications. Representation from the UCSC genome browser (NCBI36/hg18) of the NR0B1 locus on $\mathrm{Xp21.2.} \mathrm{The} \mathrm{probes} \mathrm{that} \mathrm{delineate} \mathrm{the} \mathrm{breakpoints} \mathrm{in} \mathrm{the} \mathrm{three} \mathrm{independent} \mathrm{families} \mathrm{identified} \mathrm{by} \mathrm{our} \mathrm{group} \mathrm{are} \mathrm{represented} \mathrm{by} \mathrm{red}$ vertical lines. The horizontal blue line represents the extension of the duplication in the family here described, the green lines represent the duplicated regions previously described by our group, and the orange lines represent the two duplications identified by array CGH in patients with isolate 46,XY GD by other groups. The C and P at the right ends of the lines indicate if the GD was complete or partial, respectively.

that NROB1 locus duplication should be investigated in all cases of isolated 46,XY gonadal dysgenesis.

By comparing the three small Xp21.2 duplications identified by our group, together with the other two recently reported by Ledig et al. and White et al. [11, 12] (Figure 2), it is not possible to directly delineate a genotype-phenotype correlation for the partial or complete GD forms. It is known that dosage-sensitive genes with complex expression patterns are particularly sensitive to positional effects, and regulatory regions can lie far outside the transcription unit [17]. A regulatory region upstream $N R O B 1$ has been proposed after the identification of a $257 \mathrm{~kb}$ deletion in the region between NROB1 and GK gene in a patient with XY GD [18]. Furthermore, a small inversion immediately upstream of NROB1 has been identified in a patient with congenital adrenal hypoplasia [19]. However, patients with both partial and complete form share entirely these regions in their duplications. The interaction of NROB1 with other transcription factors could also modulate the final phenotype.

Interestingly, in all cases with isolated 46,XY GD, the IL1RAPL1 gene, located immediately telomeric to the duplication containing NROB1, is not disrupted (Figure 2). Deletions or mutations of this gene have been identified in patients with mental retardation [20]. Disruption of this gene could explain the mental retardation in some previously described patients with larger Xp21 duplications.
As all three duplications we identified were maternally inherited, we could use the material available to investigate the X-inactivation pattern of the duplicated X. In several studies where a larger Xp21 duplication was maternally inherited, it was shown that the duplicated $\mathrm{X}$ was preferentially inactivated $[21,22]$. Thus carrier women are thought to be protected from a double NROB1 dose on the gene expression level. Therefore, we investigated if there was a preferential methylation of the duplicated X chromosome also in females carrying the small duplications which contain fewer deleterious genes. Analysis in lymphocytes of the three mothers showed that there is no obvious preferential inactivation of the duplicated X. Even though we could not investigate the situation directly in the ovary, we can hypothesize that healthy carrier women are fertile because the ovary, in contrast to the testis, can tolerate an extra dose of NROB1.

In conclusion, the identification of NROB1 locus duplications in patients/families, originating from different countries (Iran [9], Italy [10], England (this study), Germany [11], and Australia [12] stresses the importance of using methods that can detect submicroscopic duplications of the region surrounding NROB1 in the evaluation of patients with isolated 46,XY GD (complete or partial). The lack of phenotype in the carrier mothers and the pedigree of the family here described also illustrate that such duplications can be 
spread through the female line in the family. In the present family there are seven mandatory female carriers and nine potential carriers. In fact, some of these could even be affected XY females who have not been investigated. Small duplications are most probably more frequent, but have escaped detection due to the methods that have been used so far and the selection of the patients investigated. We believe that in a patient with isolated XY GD, the NROB1 locus should be carefully investigated. MLPA and array-CGH are two different techniques that can be applied. Array$\mathrm{CGH}$ offers the advantage of a whole genome screening approach; however, the capacity to detect very small NROB1 duplications depends on the platform used (number and distance of probes within the NROB1 locus). NROB1 has a size of $5 \mathrm{~kb}$, and the two nearest AluSx sequences on opposite side of NROB1 are only $14 \mathrm{~kb}$ apart. MLPA containing specific probes guarantees the identification, of isolated NROB1 duplications and the maternal sample can be simultaneously analysed for carrier status at a limited extra cost compared to array CGH.

\section{Acknowledgments}

This work was supported by the Stiftelsen Frimurare Barnhuset (to MB), the Swedish Research Council (Grant No. 12198), the Novo Nordisk Foundation, Karolinska Institutet, and the Stockholm County Council (to AW).

\section{References}

[1] B. Bardoni, E. Zanaria, S. Guioli et al., "A dosage sensitive locus at chromosome Xp21 is involved in male to female sex reversal," Nature Genetics, vol. 7, no. 4, pp. 497-501, 1994.

[2] B. Dabovic, E. Zanaria, B. Bardoni et al., "A family of rapidly evolving genes from the sex reversal critical region in Xp21," Mammalian Genome, vol. 6, no. 9, pp. 571-580, 1995.

[3] A. Swain, E. Zanaria, A. Hacker, R. Lovell-Badge, and G. Camerino, "Mouse Daxl expression is consistent with a role in sex determination as well as in adrenal and hypothalamus function,” Nature Genetics, vol. 12, no. 4, pp. 404-409, 1996.

[4] K. K. Niakan and E. R. B. McCabe, "DAX1 origin, function, and novel role," Molecular Genetics and Metabolism, vol. 86, no. 1-2, pp. 70-83, 2005.

[5] A. Swain, V. Narvaez, P. Burgoyne, G. Camerino, and R. Lovell-Badge, "Dax1 antagonizes Sry action in mammalian sex determination," Nature, vol. 391, no. 6669, pp. 761-767, 1998.

[6] B. K. Jordan, M. Mohammed, S. T. Ching et al., "Upregulation of WNT-4 signaling and dosage-sensitive sex reversal in humans," American Journal of Human Genetics, vol. 68, no. 5, pp. 1102-1109, 2001.

[7] T. Ogata and N. Matsuo, "Sex determining gene on the X chromosome short arm: dosage sensitive sex reversal," Acta Paediatrica Japonica, vol. 38, no. 4, pp. 390-398, 1996.

[8] D. Sanlaville, F. Vialard, F. Thépot et al., "Functional disomy of $\mathrm{Xp}$ including duplication of DAX1 gene with sex reversal due to $\mathrm{t}(\mathrm{X} ; \mathrm{Y})(\mathrm{p} 21.2 ; \mathrm{p} 11.3), "$ American Journal of Medical Genetics Part A, vol. 128, no. 3, pp. 325-330, 2004.

[9] M. Barbaro, M. Oscarson, J. Schoumans, J. Staaf, S. A. Ivarsson, and A. Wedell, "Isolated 46,XY gonadal dysgenesis in two sisters caused by a Xp21.2 interstitial duplication containing the DAX1 gene," Journal of Clinical Endocrinology and Metabolism, vol. 92, no. 8, pp. 3305-3313, 2007.
[10] M. Barbaro, A. Cicognani, A. Balsamo et al., "Gene dosage imbalances in patients with 46,XY gonadal DSD detected by an in-house-designed synthetic probe set for multiplex ligationdependent probe amplification analysis," Clinical Genetics, vol. 73, no. 5, pp. 453-464, 2008.

[11] S. Ledig, O. Hiort, G. Scherer et al., "Array-CGH analysis in patients with syndromic and non-syndromic XY gonadal dysgenesis: evaluation of array CGH as diagnostic tool and search for new candidate loci," Human Reproduction, vol. 25, no. 10, pp. 2637-2646, 2010.

[12] S. White, T. Ohnesorg, A. Notini et al., "Copy number variation in patients with disorders of sex development due to 46,XY gonadal dysgenesis," PLoS ONE, vol. 6, no. 3, Article ID e17793, 2011.

[13] R. C. Allen, H. Y. Zoghbi, A. B. Moseley, H. M. Rosenblatt, and J. W. Belmont, "Methylation of HpaII and HhaI sites near the polymorphic CAG repeat in the human androgen-receptor gene correlates with X chromosome inactivation," American Journal of Human Genetics, vol. 51, no. 6, pp. 1229-1239, 1992.

[14] Z. Zhang, S. Schwartz, L. Wagner, and W. Miller, "A greedy algorithm for aligning DNA sequences," Journal of Computational Biology, vol. 7, no. 1-2, pp. 203-214, 2000.

[15] J. A. Bailey, G. Liu, and E. E. Eichler, "An Alu transposition model for the origin and expansion of human segmental duplications," American Journal of Human Genetics, vol. 73, no. 4, pp. 823-834, 2003.

[16] F. Muscatelli, T. M. Strom, A. P. Walker et al., "Mutations in the DAX-1 gene give rise to both X-linked adrenal hypoplasia congentia and hypogonadotropic hypogonadism," Nature, vol. 372, no. 6507, pp. 672-676, 1994.

[17] D. A. Kleinjan and V. van Heyningen, "Long-range control of gene expression: emerging mechanisms and disruption in disease," American Journal of Human Genetics, vol. 76, no. 1, pp. 8-32, 2005.

[18] M. Smyk, J. S. Berg, A. Pursley et al., "Male-to-female sex reversal associated with an $\sim 250 \mathrm{~kb}$ deletion upstream of NR0B1 (DAX1)," Human Genetics, vol. 122, no. 1, pp. 63-70, 2007.

[19] B. Skinningsrud, E. S. Husebye, G. D. Gilfillan et al., "Xlinked congenital adrenal hypoplasia with hypogonadotropic hypogonadism caused by an inversion disrupting a conserved noncoding element upstream of the NR0B1 (DAX1) gene," Journal of Clinical Endocrinology and Metabolism, vol. 94, no. 10, pp. 4086-4093, 2009.

[20] A. Carrié, L. Jun, T. Bienvenu et al., "A new member of the IL-1 receptor family highly expressed in hippocampus and involved in X-linked mental retardation," Nature Genetics, vol. 23, no. 1, pp. 25-31, 1999.

[21] R. Bernstein, T. Jenkins, B. Dawson et al., "Female phenotype and multiple abnormalities in sibs with a Y chromosome and partial X chromosome duplication: $\mathrm{H}-\mathrm{Y}$ antigen and $\mathrm{Xg}$ blood group findings," Journal of Medical Genetics, vol. 17, no. 4, pp. 291-300, 1980.

[22] G. Scherer, W. Schempp, C. Baccichetti et al., "Duplication of an Xp segment that includes the ZFX locus causes sex inversion in man," Human Genetics, vol. 81, no. 3, pp. 291294, 1989. 


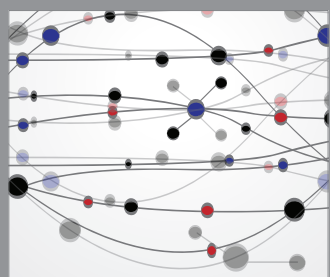

The Scientific World Journal
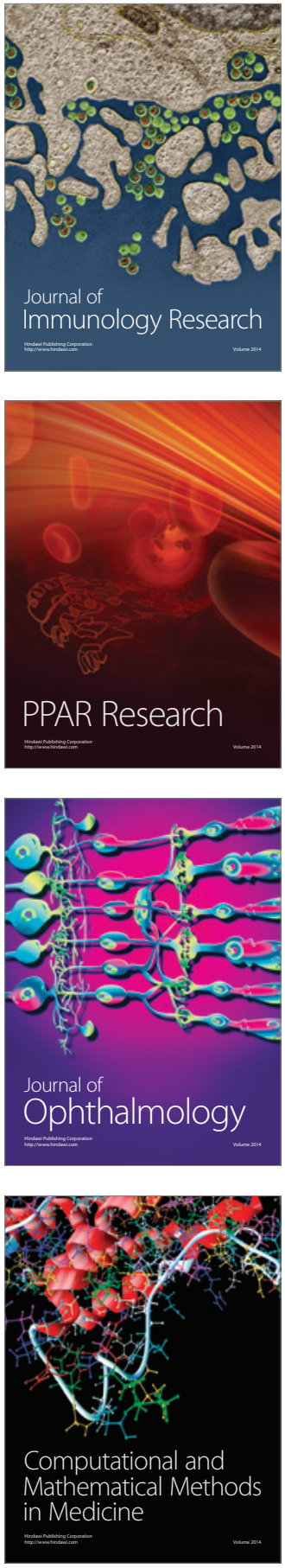

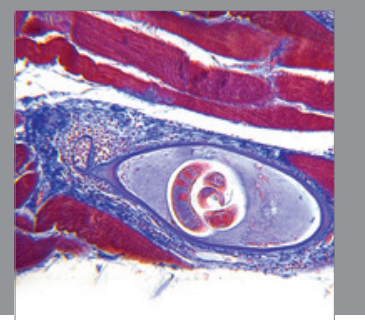

Gastroenterology

Research and Practice
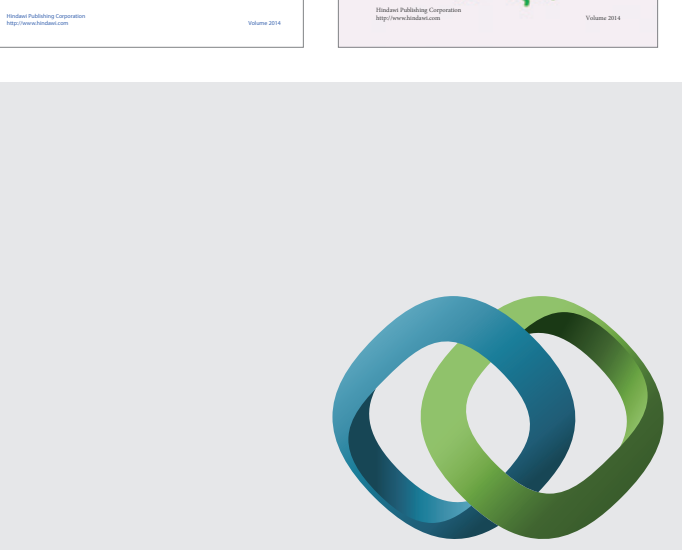

\section{Hindawi}

Submit your manuscripts at

http://www.hindawi.com
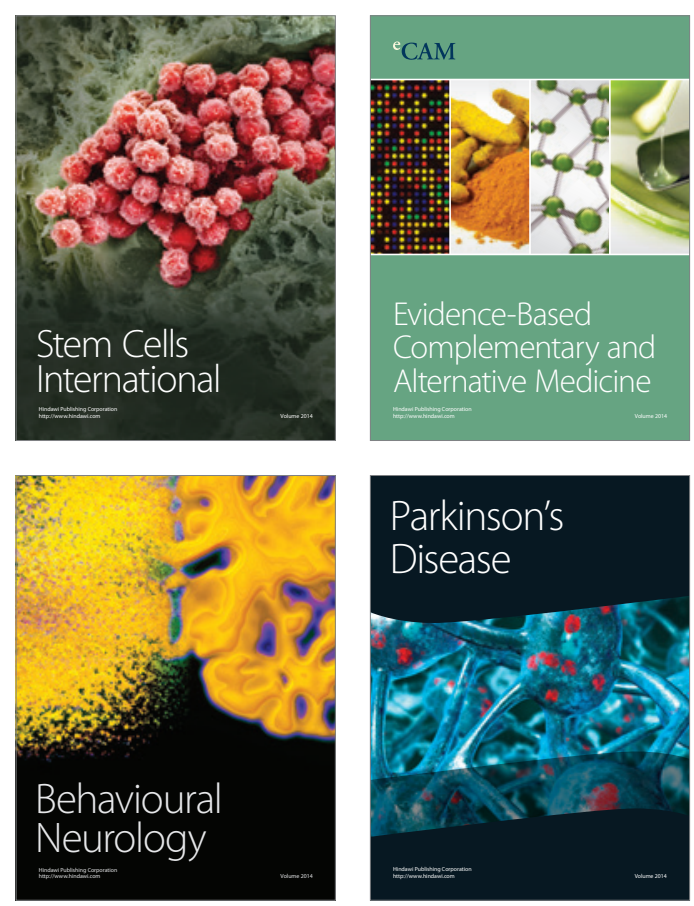

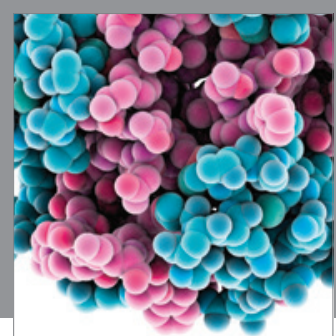

Journal of
Diabetes Research

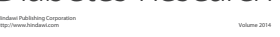

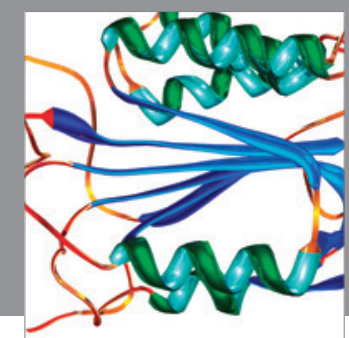

Disease Markers
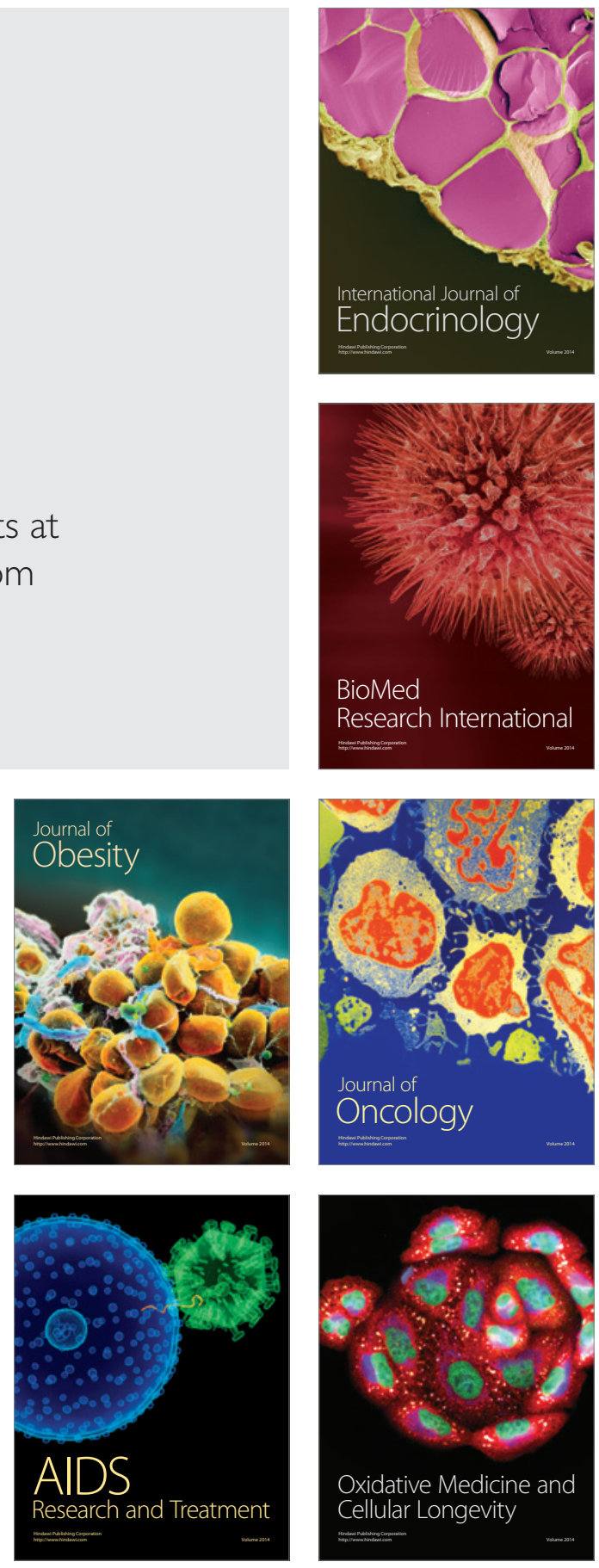